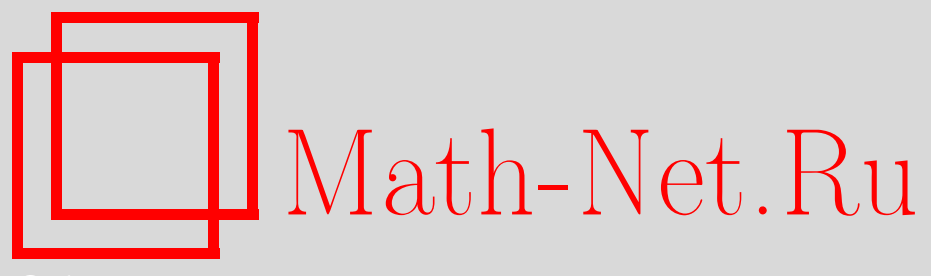

С. И. Адян, О. В. Бесов, А. А. Гончар, М. И. Дьяченко, Б. С. Кашин, С. М. Никольский, М. К. Потапов, Петр Лаврентьевич Ульянов (некролог), УМН, 2007, том 62, выпуск 4, 133-139

DOI: https://doi.org/10.4213/rm7921

Использование Общероссийского математического портала Math-Net.Ru подразумевает, что вы прочитали и согласны с пользовательским соглашением http://www . mathnet.ru/rus/agreement

Параметры загрузки:

IP: 3.80 .253 .173

26 апреля 2023 г., 12:08:22

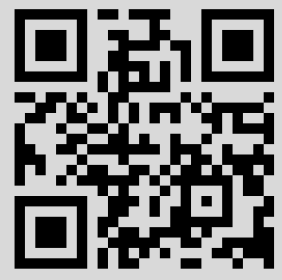




\section{Петр Лаврентьевич Ульянов}

13 ноября 2006 г. после тяжелой продолжительной болезни скончался выдающийся русский ученый-математик, действительный член Российской академии наук, заведующий кафедрой теории функций и функционального анализа Московского государственного университета Петр Лаврентьевич Ульянов.

П.Л. Ульянов родился 3 мая 1928 г. в селе Слепцовка Саратовской области в крестьянской семье. В 1945 г. он поступил на механико-математический факультет Саратовского университета, а в 1950 г. закончил его с отличием. В трудные послевоенные годы студенту Ульянову приходилось сочетать учебу с работой по вечерам, однако тяга к знаниям, настойчивость в достижении цели и помощь профессоров и преподавателей Саратовского университета позволили ему выйти далеко за рамки стандартной университетской программы и подготовить себя к самостоятельной научной работе.

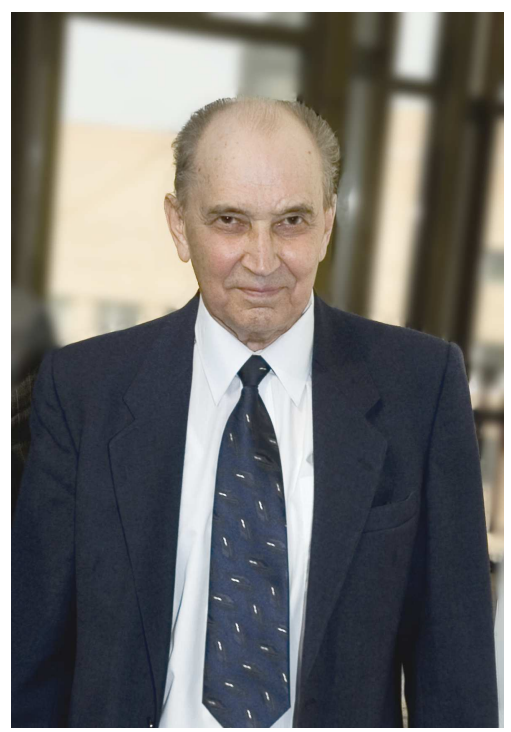

Осенью 1950 г. П. Л. Ульянов поступает в аспирантуру механико-математического факультета МГУ. С тех пор его жизнь была неразрывно связана с Московским университетом. Пятидесятые годы прошлого века были периодом особого подъема интереса молодежи к математике и не случайно среди воспитанников мехмата МГУ тех лет - целый ряд выдающихся ученых.

Научным руководителем П. Л. Ульянова в аспирантуре была Нина Карловна Бари, от нее Петр Лаврентьевич унаследовал интерес к тригонометрическим и общим ортогональным рядам. С первых дней обучения в аспирантуре Петр Лаврентьевич стал активным участником "лузинского" семинара по теории функций действительного переменного, работу которого возглавляли в то время Н. К. Бари и Д. Е. Меньшов. Здесь он научился у Дмитрия Евгеньевича Меньшова такому “въедливому" отношению к делу, которое было свойственно ему до конца дней.

Активную деятельность семинара, работой которого сам Петр Лаврентьевич руководил с 1959 г. до конца жизни, он считал своей постоянной задачей, важнейшим условием развития теории функций в Москве.

Тему кандидатской диссертации П. Л. Ульянов выбрал под влиянием А. Н. Колмогорова, предложившего исследовать важный для теории тригонометрических рядов обобщенный интеграл, так называемый $A$-интеграл. Одним из основных результатов диссертации, защищенной в 1953 г. (оппоненты: А. Н. Колмогоров и Д. Е. Меньшов), 
была теорема об $A$-интегрируемости функций, представимых тригонометрическими рядами с монотонными коэффициентами, и их сопряженных. Результаты П. Л. Ульянова, входившие в кандидатскую диссертацию, были отмечены премией Московского математического общества за 1954 г. С 1 сентября 1953 г. Петр Лаврентьевич работал на кафедре теории функций и функционального анализа мехмата МГУ сначала ассистентом, затем с 1956 г. доцентом и с 1960 г. профессором, а с 1979 г. до конца жизни заведующим кафедрой. Кроме того, П. Л. Ульянов более 40 лет работал по совместительству в отделе теории функций Математического института им. В. А. Стеклова.

$A$-интеграл был использован и в защищенной П. Л. Ульяновым в 1960 г. докторской диссертации "Интеграл Коши. Сходимость и суммируемость". Основным результатом первой части этой работы является теорема о восстановлении аналитической функции $F(z)$, определенной в области достаточно общего вида, ограниченной спрямляемым замкнутым контуром $\gamma$, интегралом типа Коши с помощью формулы

$$
F(z)=\frac{1}{2 \pi}(A) \int_{\gamma} \frac{F_{\text {int }}(z)}{u-z} d u
$$

в которой $F_{\text {int }}(u)(u \in \gamma)$ - угловые предельные значения функции $F(z)$, интеграл понимается в обобщенном смысле как $A$-интеграл.

Диссертация П. Л. Ульянова была высоко оценена ученым советом механико-математического факультета МГУ и по предложению П. С. Александрова и А. О. Гельфонда после специального голосования признана выдающейся.

С начала 60-х годов Петр Лаврентьевич, фактически возглавив, вместе с Д.Е. Меньшовым, московскую школу метрической теории функций, начинает реализацию широкой программы исследований, а затем привлекает к ней своих учеников и последователей. Исключительно полезную роль сыграли в то время обзорные статьи П. Л. Ульянова в "Успехах математических наук", содержащие постановки целого ряда новых, важных задач. Надо особо отметить способность Петра Лаврентьевича "остро" поставить новую математическую задачу и тем самым привлечь к интересующему его направлению исследований способную молодежь. Многие известные математики отмечают, что работа над поставленной перед ними П.Л. Ульяновым задачей существенно повлияла на их научную судьбу.

Работы самого Петра Лаврентьевича Ульянова, выполненные после защиты докторской диссертации, относятся в основном к двум важным областям анализа:

- ортогональные и общие функциональные ряды,

- теоремы вложения и пространства функций.

В теории ортогональных рядов П. Л. Ульяновым было начато систематическое исследование свойств ортогональной системы Хаара. Им установлены ставшие теперь классическими оценки коэффициентов Фурье-Хаара и неравенства для погрешности приближения функций полиномами по системе Хаара, исследованы различные виды сходимости рядов Фурье-Хаара. Последующее развитие теории ортогональных рядов и, в частности, бурное развитие в 80 -е годы прошлого века теории и приложений всплеск-систем, частным случаем которых является система Хаара, подтвердило правильность выбора направления исследований, сделанного П. Л. Ульяновым. Петр Лаврентьевич применил результаты о системе Хаара к исследованию общих ортогональных и функциональных рядов. Проведенное им исследование безусловной сходимости почти всюду рядов Хаара позволило ему дать первый, принципиально важный пример функционального ряда

$$
\sum_{n=1}^{\infty} f_{n}(x)
$$


сходящегося почти всюду при всех выборах знаков (т. е. такого, что все ряды вида

$$
\sum_{n=1}^{\infty} \varepsilon_{n} f_{n}(x), \quad \varepsilon_{n}= \pm 1
$$

сходятся почти всюду), для которого после некоторой перестановки $\sigma$ его членов ряд

$$
\sum_{n=1}^{\infty} f_{\sigma(n)}(x)
$$

расходится почти всюду.

С использованием тех же результатов П. Л. Ульянова о системе Хаара самим Петром Лаврентьевичем и, независимо, его учеником А. М. Олевским была установлена теорема о несуществовании полных ортонормированных систем безусловной сходимости. В 60-70-е годы прошлого века направление в теории ортогональных рядов, открытое этой теоремой и связанное с переносом на общие ортогональные системы результатов о классических ортогональных системах, занимало одно из центральных мест.

Начало новому направлению в теории функций положили и работы П. Л. Ульянова по теоремам вложения, выполненные в конце 60-х - начале 70-х годов. В этих работах были получены необходимые и достаточные условия на модуль непрерывности $\omega(\delta)$, обеспечивающие вложение класса $H_{p}^{\omega}$ функций, имеющих "гладкость" $\omega(\delta)$ в $L^{p}(0,1)$, в пространство Лебега $L^{q}$ или пространство липшицевых (по норме $L^{q}$ ) функций $\operatorname{Lip}(\alpha, q)$. Здесь результаты П. Л. Ульянова завершили исследования, начатые еще Харди и Литлвудом. Метод, примененный Петром Лаврентьевичем, основанный на исследовании экстремальных свойств модуля непрерывности в пространстве $L^{p}$ монотонной функции, равноизмеримой с данной функцией, оказался весьма плодотворным и получил развитие в работах многих математиков.

Глубокие результаты были получены Петром Лаврентьевичем в циклах работ, посвященных исследованию классов $\varphi(L)$, классам бесконечно дифференцируемых функций, алгебрам функций.

В целом работы П. Л. Ульянова и его школы (а среди прямых учеников П. Л. Ульянова 50 кандидатов и 15 докторов наук) оказали глубокое влияние на развитие теории функций во второй половине ХХ века. Выдающаяся роль Петра Лаврентьевича Ульянова в подготовке математических кадров не ограничивалась воспитанием своих прямых учеников. Сотни математиков из разных городов нашей страны, республик бывшего СССР и дальнего зарубежья с благодарностью вспоминают неповторимую творческую обстановку научных семинаров, проходивших под его руководством. Исключительная энергия и работоспособность П. Л. Ульянова позволяли ему совмещать активную работу в редколлегиях ведущих математических журналов, экспертном совете по математике и механике BAK с организацией десятков научных школ и конференций. С особым вниманием и заботой Петр Лаврентьевич относился к организации зимних школ по теории функций и приближений в своем родном городе - Саратове. Многие саратовские (и, конечно, не только саратовские) математики получили на этих школах путевки в научную жизнь. А ведь при самом активном участии П.Л. Ульянова регулярно, даже в тяжелые 90-е годы прошлого века, проводились еще и школы в Воронеже, Казани и других городах.

За выдающийся вклад в науку П.Л. Ульянов в 1981 г. был избран членом-корреспондентом АН СССР, а в мае 2006 г. - действительным членом РАН. Кроме того, он являлся действительным членом Международной академии наук высшей школы и заслуженным профессором МГУ. П.Л. Ульянов был награжден орденами СССР, ему была присуждена Государственная премия Российской Федерации. 
Вся жизнь академика П.Л. Ульянова является примером беззаветного служения отечественной науке. Светлая память о Петре Лаврентьевиче Ульянове навсегда сохранится в наших сердцах.

С.И. Адян, О.В. Бесов, А.А. Гончар, М.И. Дъяченко, Б. С. Кашин, С. М. Никольский, М. К. Потапов

\section{Список печатных работ П.Л. Ульянова}

[207] "Юрий Александрович Казьмин (некролог)", УМН, 51:1 (1996), 137-138 (совм. с А.А. Гончаром, О.Б. Лупановым, В.А. Садовничим); англ. пер.: "Yurii Aleksandrovich Kaz'min (obituary)", Russian Math. Surveys, 51:1 (1996), 135-136 (with A. A. Gonchar, O. B. Lupanov, V. A. Sadovnichii).

[208] "Вторая Казанская школа-конференция «Теория функций и ее приложения»", УМН, 51:1 (1996), 183-184 (совм. с Л.А. Аксентьевым, А. М. Елизаровым, С. Р. Насыровым).

[209] “Евгений Михайлович Никишин (к пятидесятилетию со дня рождения)", УМН, 51:2 (1996), 181-182 (совм. с С. П. Новиковым, А. И. Аптекаревым, Е. П. Долженко, В.А. Калягиным, В.В.Козловым, Ю. В. Нестеренко, М. К. Потаповым, В.Н. Сорокиным); англ. пер.: "Evgenii Mikhailovich Nikishin (on the fiftieth anniversary of his birth)", Russian Math. Surveys, 51:2 (1996), 361-362 (with S. P. Novikov, A. I. Aptekarev, E. P. Dolzhenko, V. A. Kalyagin, V. V. Kozlov, Yu. V. Nesterenko, M. K. Potapov, V. N. Sorokin).

[210] “Александр Васильевич Ефимов (к семидесятилетию со дня рождения)", УМН, 51:3 (1996), 219-220 (совм. с Л. Д. Кудрявцевым, С. М. Никольским, А. С. Поспеловым, С. Б. Стечкиным, С. А. Теляковским); англ. пер.: "Aleksandr Vasil'evich Efimov (on his seventieth birthday)", Russian Math. Surveys, 51:3 (1996), 581-583 (with L. D. Kudryavtsev, S. M. Nikol'skii, A. S. Pospelov, S. B. Stechkin, S. A. Telyakovskii, P. L. Ul'yanov).

[211] "Восьмая Саратовская зимняя школа «Современные проблемы теории функций и их приложения»", УМН, 51:3 (1996), 221-222 (совм. с А. Л. Лукашовым, Д. И. Трубецким, А. П. Хромовым).

[212] “Сергей Борисович Стечкин (некролог)", УМН, 51:6 (1996), 3-10 (совм. с О.В. Бесовым, В.М. Бухштабером, А.Г. Витушкиным, А.А. Гончаром, С. В. Конягиным, Л.Д. Кудрявцевым, С. М. Никольским, С. П. Новиковым, Ю.С. Осиповым, А.Ю. Поповым, В.А. Садовничим, А.Ф. Сидоровым, Ю.Н. Субботиным, С.А. Теляковским, Н. И. Черных); англ. пер.: "Sergei Borisovich Stechkin (obituary)", Russian Math. Surveys, 51:6 (1996), 1007-1014 (with O. V. Besov, V. M. Buchstaber, A. G. Vitushkin, A. A. Gonchar, S. V. Konyagin, L. D. Kudryavtsev, S. M. Nikol'skii, S. P. Novikov, Yu. S. Osipov, A. Yu. Popov, V. A. Sadovnichii, A.F. Sidorov, Yu. N. Subbotin, S. A. Telyakovskii, N. I. Chernykh).

[213] "Воспоминания о Сергее Борисовиче Стечкине”, УМН, 51:6 (1996), 11-20; англ. пер.: "Reminiscences of Sergei Borisovich Stechkin", Russian Math. Surveys, 51:6 (1996), 1015-1024.

[214] “О рядах Фурье-Хаара от суперпозиций функций”, Докл. РАН, 350:1 (1996), 25-28; англ. пер.: "On Fourier-Haar series of superpositions of functions", Dokl. Math., 54:2 (1996), 665-668.

Начало списка опубликовано в кн.: Математика в СССР за сорок лет. 1917-1957, т. 2, Физматгиз, М., 1959, 694; и Математика в СССР. 1958-1967, т. 2, Наука, М., 1970, 1342-1343, а также в УМН, 43:4 (1988), 246-249; 53:3 (1998), 211-220. 
[215] П. Л. Ульянов (ред.), Современные проблемы теории функиий и их приложения, Тезисы докладов 8-й Саратовской зимней школы (Саратов, 1996), Изд-во Саратов. ун-та, Саратов, 1996.

[216] "Семен Яковлевич Хавинсон (к семидесятилетию со дня рождения)", УМН, 52:3 (1997), 187-188 (совм. с А. Г. Витушкиным, А. А. Гончаром, М. В. Самохиным); англ. пер.: "Semen Yakovlevich Khavinson (on his 70th birthday)", Russian Math. Surveys, 52:3 (1997), 631-633 (with A. G. Vitushkin, A. A. Gonchar, M. V. Samokhin).

[217] “К восьмидесятилетию Алексея Федоровича Леонтьева (1917-1987)", УМН, 52:3 (1997), 189-190 (совм. с А. Г. Витушкиным, В. С. Владимировым, А. А. Гончаром, В. В. Напалковым, С. М. Никольским, А. М. Седлецким, Ю. Н. Фроловым); англ. пер.: "Aleksei Fedorovich Leont'ev (1917-1987) (on the 80th anniversary of his birth)", Russian Math. Surveys, 52:3 (1997), 635-637 (with A. G. Vitushkin, V.S. Vladimirov, A. A. Gonchar, V. V. Napalkov, S. M. Nikol'skii, A. M. Sedletskii, Yu. N. Frolov).

[218] “Школа «Современные методы теории функций и смежные проблемы»", УМН, 52:4 (1997), 251-252 (совм. с В. В. Гусев, Ю. В. Покорный).

[219] “Вторая Казанская школа-конференция «Алгебра и анализ»", УМН, 52:6 (1997), 215-215 (совм. с А. М. Елизаровым, С. Р. Насыровым, А. Н. Шерстневым).

[220] "О модулях непрерывности и рядах Фурье-Хаара", Докл. РАН, 355:5 (1997), 612-615; англ. пер.: "Modules of continuity and the Fourier-Haar series", Dokl. Math., 56:1 (1997), 593-596.

[221] П. Л. Ульянов (ред.), Современные проблемы теории функиий и их приложения, Тезисы докладов 9-й Саратовской зимней школы (Саратов, 1998), Изд-во Саратов. ун-та, Саратов, 1997.

[222] "Девятая Саратовская зимняя школа «Современные проблемы теории функций и их приложения»”, УМН, 53:2 (1998), 185-186 (совм. с А. Л. Лукашовым, Д. И. Трубецким, А. П. Хромовым).

[223] "О свойствах рядов по системе Хаара", Докл. РАН, 361:1 (1998), 31-34; англ. пер.: "On the properties of Haar expansions", Dokl. Math., 58:1 (1998), 25-28.

[224] "Об А-сходимости рядов", Докл. РАН, 368:2 (1999), 160-163; англ. пер.: P. L. Ul'yanov, "On the A-convergence of series", Dokl. Math., 60:2 (1999), 176-179.

[225] “«Современные методы теории функций и смежные проблемы» на Воронежской зимней математической школе”, УМН, 55:2 (2000), 189-190 (совм. с Ю. В. Покорным, А. В. Боровских).

[226] “Третья Казанская школа-конференция «Теория функций, ее приложения и смежные вопросы»", УМН, 55:3 (2000), 205-206 (совм. с А. М. Елизаровым, C. Р. Насыровым).

[227] "О свойствах рядов", Докл. РАН, 373:3 (2000), 307-310; англ. пер.: "On the properties of series", Dokl. Math., 62:1 (2000), 56-59.

[228] "The influence of Andreŭ Nikolaevich Kolmogorov on my life", Kolmogorov in perspective, Hist. Math., 20, Amer. Math. Soc., Providence, RI, 2000, 121-140.

[229] "Краткий обзор научной деятельности Э. А. Стороженко", Укр. матем. журн., 52:4 (2000), 463-473 (совм. с Б. С. Кашиным, Н. П. Корнейчуком, И. А. Шевчуком, В.А. Андриенко); англ. пер.: "A brief survey of the scientific work of Ł̀. A. Storozhenko", Ukrainian Math. J., 52:4 (2000), 531-542 (with B. S. Kashin, N. P. Korneı̆chuk, I. A. Shevchuk, V. A. Andrienko). 
[230] "Юлий Витальевич Покорный (к шестидесятилетию со дня рождения)", УМН, 56:1 (2001), 199-200 (совм. с В. А. Ильиным, С. М. Никольским, Н. Х. Розовым, А. П. Хромовым); англ. пер.: "Yulii Vital'evich Pokornyi (on his 60th birthday)", Russian Math. Surveys, 56:1 (2001), 197-199 (with V.A. Il'in, S. M. Nikol'skii, N. Kh. Rozov, A. P. Khromov).

[231] “Анатолий Михайлович Степин (к шестидесятилетию со дня рождения)", УМН, 56:1 (2001), 201-204 (совм. с Д. В. Аносовым, А. А. Болибрухом, А. М. Вершиком, А.А. Гончаром, Р. И. Григорчуком, В. В. Козловым, В.П. Масловым, Е.Ф. Мищенко, Я. Г. Синаем, В. М. Тихомировым, А. Т. Фоменко); англ. пер.: "Anatolii Mikhailovich Stepin (on his 60th birthday)", Russian Math. Surveys, 56:1 (2001), 201-205 (with D. V. Anosov, A. A. Bolibrukh, A. M. Vershik, A. A. Gonchar, R. I. Grigorchuk, V.V. Kozlov, V.P. Maslov, E. F. Mishchenko, Ya. G. Sinai, V. M. Tikhomirov, A. T. Fomenko).

[232] "Десятая Саратовская зимняя школа «Современные проблемы теории функций и их приложения»", УМН, 56:1 (2001), 205-206 (совм. с Д. И. Трубецким, А. П. Хромовым, А. Л. Лукашовым).

[233] "Воронежская зимняя математическая школа «Современные методы теории функций и смежные проблемы»”, УМН, 56:4 (2001), 185-186 (совм. с Ю. В. Покорным, А. В. Боровских).

[234] "Пятая Казанская международная летняя школа-конференция «Теория функций, ее приложения и смежные вопросы»", УМН, 56:6 (2001), 183-184 (совм. с А. М. Елизаровым, С. Р. Насыровым).

[235] "Михаил Константинович Потапов (к семидесятилетию со для рождения)", Вестн. Моск. ун-та. Сер. 1. Матем., мех., 2001, №1, 66-67 (совм. с С. М. Никольский).

[236] "О преобразованиях некоторых классов рядов Фурье-Хаара", Докл. РАН, 379:3 (2001), 305-308; англ. пер.: "Transformations of some classes of Fourier-Haar series", Dokl. Math., 64:1 (2001), 53-56.

[237] "О теоремах Леви и Марцинкевича для системы Хаара", Труды матем. иентра им. Н. И. Лобачевского, 8, 2001, 225-227; англ. пер.: "On Lévy and Marcinkiewicz theorems for Fourier-Haar series", J. Contemp. Math. Anal., 36:4 (2001), 77-85.

[238] “Анатолий Георгиевич Витушкин (к семидесятилетию со дня рождения)", УМН, 57:1 (2002), 179-184 (совм. с В. К. Белошапкой, В. С. Владимировым, А. А. Гончаром, Е. П. Долженко, Н. Г. Кружилиным, В. В. Напалковым, П. В. Парамоновым, А. Г. Сергеевым, Е. М. Чиркой); англ. пер.: "Anatolii Georgievich Vitushkin (on his 70th birthday)", Russian Math. Surveys, 57:1 (2002), 183-190 (with V. K. Beloshapka, V. S. Vladimirov, A. A. Gonchar, E. P. Dolzhenko, N. G. Kruzhilin, V. V. Napalkov, P. V. Paramonov, A. G. Sergeev, E. M. Chirka).

[239] “Андрей Александрович Гончар (к семидесятилетию со дня рождения)", УМН, 57:1 (2002), 185-190 (совм. с А. А. Болибрухом, А. Г. Витушкиным, В. С. Владимировым, Е.Ф. Мищенко, С.П. Новиковым, Ю. С. Осиповым, А.Г. Сергеевым, Л. Д. Фаддеевым, Е. М. Чиркой); англ. пер.: "Andrei Aleksandrovich Gonchar (on his 70th birthday)", Russian Math. Surveys, 57:1 (2002), 191-198 (with A. A. Bolibrukh, A. G. Vitushkin, V. S. Vladimirov, E. F. Mishchenko, S. P. Novikov, Yu. S. Osipov, A. G. Sergeev, L. D. Faddeev, E. M. Chirka).

[240] “Александр Васильевич Ефимов (некролог)", УМН, 57:3 (2002), 135-136 (совм. с С. М. Никольским, А. С. Поспеловым, С.А. Теляковским, С. В. Умняшкиным, Ю. А. Чаплыгиным); англ. пер.: "Alexandr Vasil'evich Efimov (obituary)", Russian Math. Surveys, 57:3 (2002), 573-575 (with S. M. Nikol'skii, A. S. Pospelov, S. A. Telyakovskii, S. V. Umnayshkin, Yu. A. Chaplugin). 
[241] "On interconnections between the research of Russian and Polish mathematicians in the theory of functions", Fourier analysis and related topics (Bedlewo, 2000), Banach Center Publ., 56, Polish Acad. Sci., Warsaw, 2002, 119-130.

[242] "О равномерной сходимости тригонометрических рядов", Докл. РАН, 387:1 (2002), 19-25; англ. пер.: "Uniform convergence of trigonometric series", Dokl. Math., 66:33 (2002), 316-321.

[243] Мера и интеграл, Факториал, М., 2002 (совм. с М. И. Дьяченко).

[244] "On interconnections between the research of Russian and Polish mathematicians in the theory of functions", Fourier analysis and related topics (Bedlewo, 2000), Banach Center Publ., 56, Polish Acad. Sci., Warsaw, 2002, 119-130.

[245] "Современные методы теории функций и смежные проблемы", УМН, 58:4 (2003), 177-178 (совм. с Ю. В. Покорным, А. В. Боровских).

[246] "О расходящихся рядах Фурье по ортогональным системам с ограниченными вариациями”, Докл. РАН, 390:3 (2003), 309-313 (совм. с К. С. Казаряном); англ. пер.: "On diverging Fourier series in orthogonal systems with bounded variations", Dokl. Math., 67:3 (2003), 357-361 (with K. S. Kazaryan).

[247] "Двенадцатая Саратовская зимняя школа «Современные проблемы теории функций и их приложения»”, УМН, 59:3 (2004), 189-190 (совм. с Л. Ю. Коссовичем, А. Л. Лукашовым, А. П. Хромовым).

[248] "Семен Яковлевич Хавинсон (некролог)", УМН, 59:4 (2004), 186-192 (совм. с А.Г. Витушкиным, А.А. Гончаром, М.В. Самохиным, В.М. Тихомировым, П.Л.Ульяновым, В.П. Хавиным, В.Я. Эйдерманом); англ. пер.: "Semen Yakovlevich Khavinson (obituary)", Russian Math. Surveys, 59:4 (2004), 777-785 (with A. G. Vitushkin, A. A. Gonchar, M. V. Samokhin, V. M. Tikhomirov, V.P. Havin, V. Ya. Eiderman).

[249] "Воронежская зимняя математическая школа «Современные методы теории функций и смежные проблемы»”, УМН, 60:3 (2005), 185-186 (совм. с Ю. В. Покорным, С. А. Шабровым).

[250] "Карой Тандори (некролог)", УМН, 61:1 (2006), 165-168 (совм. с Б. И. Голубовым, С.М. Никольским, С.А. Теляковским); англ. пер.: "Károly Tandori (obituary)", Russian Math. Surveys, 61:1 (2006), 161-164 (with B.I. Golubov, S. M. Nikol'skii, S. A. Telyakovskii).

[251] "Андрей Борисович Шидловский (к девяностолетию со дня рождения)", УмH, 61:2 (2006), 183-190 (совм. с В.В. Козловым, О.Б. Лупановым, Ю.В.Нестеренко, М.К. Потаповым, В.А. Садовничим); англ. пер.: "Andrei Borisovich Shidlovskii (on his 90th birthday)", Russian Math. Surveys, 61:2 (2006), 379-386 (with V.V. Kozlov, O. B. Lupanov, Yu. V. Nesterenko, M. K. Potapov, V. A. Sadovnichii). 